\title{
Blocking with serial and simultaneous compounds in a trace conditioning procedure
}

\author{
ELIZABETH A. KOHLER and JOHN J. B. AYRES \\ University of Massachusetts, Amherst, Massachusetts
}

\begin{abstract}
Blocking of conditioned suppression in rats was studied in three experiments using serial and simultaneous compounds in Pavlovian trace conditioning procedures. Experimental groups were first given trace conditioning trials with a 2-sec stimulus (A) presented at least $60 \mathrm{sec}$ before an electric grid shock US. Next, both experimental and control groups received reinforced trials with a compound stimulus (AB). Both $A$ and $B$ were 2 sec in duration and were presented at least $60 \mathrm{sec}$ before the US. For some groups during $A B$ training, the $A$ stimulus preceded the B stimulus; for others, B preceded A; for still others, A and B occurred simultaneously. Conditioning was subsequently assessed separately to both $A$ and $B$. The results were as follows: First, varying the interval between the onset of $A$ and the US during $A$ training appeared to produce significantly different levels of conditioning to $A$ but did not detectably affect A's ability to block conditioning to B. Second, blocking was observed in both simultaneous and serial procedures. Third, in the serial procedure, A blocked conditioning to $B$ whether it preceded $\mathrm{B}$ or followed $\mathrm{B}$ in the $\mathrm{AB}$ compound. Fourth, in tests given after $\mathrm{AB}$ conditioning, the experimental and control groups suppressed similarly to $A$. The relevance of these results to the conditioning model of Rescorla and Wagner (1972) and to Mackintosh's (1975b) theory of attention are discussed.
\end{abstract}

Prior conditioning of element $\mathbf{A}$ of a compound conditioned stimulus (CS) consisting of elements A and B has been found to "block" conditioning to the B element (Kamin, 1968, 1969). One influential theory that has been proposed to account for such blocking suggests that elements of a compound CS compete for a limited amount of associative strength. Therefore, conditioning to the $\mathrm{B}$ element must be inversely proportional to the conditioned strength of the A element (Rescorla \& Wagner, 1972). This socalled "inverse hypothesis" guided much of the present research.

The immediate motivation behind the present studies grew out of a series of unpublished experiments performed in this laboratory testing the idea that blocking can occur even when the A element consists of an entire conditioning context or stable apparatus cues and the $\mathrm{B}$ element is a discrete, dynamic CS. Although other workers had found support for this idea (e.g., Tomie, 1976a, 1976b), our experiments consistently failed.

This study is based upon a doctoral dissertation submitted by E. A. Kohler to the University of Massachusetts, Amherst, in 1979 in partial fulfillment of the requirements for the $\mathrm{PhD}$ degree. The research was funded by Grant MH 28226-01 awarded to John J. B. Ayres by the National Institute of Mental Health and was directed by him. The authors would like to thank J. W. Donahoe, A. Well, and V. Dethier, who served as members of the dissertation committee. The authors' mailing address is: Department of Psychology, University of Massachusetts, Amherst, Massachusetts 01003.
In the unpublished studies, a discrete CS, element $A$, was first conditioned in Phase 1 by repeatedly pairing it in a conditioned suppression situation (Estes \& Skinner, 1941) with an electric-shock unconditioned stimulus (US). Then, in Phase 2, the preconditioned $A$ cue was turned on part way into each session and left on as though it were a static apparatus cue. Embedded within this $A$ cue were reinforced presentations of a discrete CS, element B.

Since the preconditioned $A$ cue failed to block conditioning to $B$, reasons for this failure were sought. The data were first examined to see if extinction of conditioning to $A$ in the intervals between presentations of $B$ could have led to the unblocking (cf. Kamin, 1968; Wagner, 1969). Although this possibility could not be completely ruled out, the data did not look promising and so other explanations were sought.

One possibility tested was as follows: In Phase 1, the US occurred a relatively short time after the onset of stimulus $A$; but during $A B$ training, the US was much further removed from A's onset. Perhaps the arrival of the US at this new time was "surprising," and perhaps it was this surprise that produced the unblocking (cf. Kamin, 1968, 1969). In a direct experimental test of this hypothesis, however, Kohler and Ayres (1979) found no support for it.

The next possibility tested was this: In Phase 1, stimulus A never extended beyond US termination, but in Phase 2, A invariably extended beyond the termination of both the US and the B element. Per- 
haps this unexpected extension of $\mathbf{A}$ constituted a "posttrial surprise" of the type found by Gray and Appignanesi (1973) to produce unblocking. This possibility was tested directly by Ayres and Bombace (1982) and by Ayres and Vigorito (Note 1), and no support for it was found either.

The present research began as an effort to test yet a third possibility: In Phase 2, the onset of the B element was closer to the time of US onset than was the onset of the A element. Perhaps this difference in the interstimulus intervals (ISIs) favored conditioning to B in Phase 2 and was somehow responsible for the unblocking that was observed.

In the present research, a trace conditioning procedure was chosen to test this hypothesis. One reason for this choice was that the effects of different ISIs in the trace procedure are well known (Kamin, 1965), so that intervals guaranteed to be more favorable for element B than for element A could be selected. In addition, much less work on blocking has been done with trace than with delay procedures, and so the hope was that the present studies could enhance our knowledge of blocking in the trace situation regardless of the merits of the particular hypothesis the trace procedure was chosen to test.

\section{EXPERIMENT 1}

In Phase 1, one experimental group (Group 62E) received a series of conditioning trials on which a 2 -sec occurrence of stimulus A began $62 \mathrm{sec}$ prior to the US onset. In Phase 2, each trial consisted of a 2 -sec occurrence of the $\mathrm{AB}$ compound beginning $62 \mathrm{sec}$ prior to US onset. This group was expected to show strong blocking of conditioning to $\mathrm{B}$ relative to that seen in a control group (Group 62C), which received only the $A B$ training with a 62 -sec ISI between the onset of the AB compound and the US. Of greater interest were the anticipated results of a second experimental group, Group 105E. In Phase 1, this group's trials consisted of a 2-sec occurrence of stimulus A beginning $105 \mathrm{sec}$ prior to US onset. Then, in Phase 2, each trial consisted of a 2-sec occurrence of $A$, whose onset was followed $43 \mathrm{sec}$ later by a 2-sec occurrence of B and $105 \mathrm{sec}$ later by the onset of the US. Thus, A and B were presented in serial compound, and the ISIs between CS elements and US onset were $105 \mathrm{sec}$ for $A$ and $62 \mathrm{sec}$ for B. There are two reasons why Group 105E should show stronger conditioning than Group $62 \mathrm{E}$ to stimulus B. First, assuming conditioning to B to be inversely related to the conditioned strength of $A$, we should expect Group 105E to show more conditioning to $\mathrm{B}$ because $\mathrm{A}$ should be more poorly conditioned in Group 105E than in Group 62E. Second, in Phase 2, the ISIs between $A$ and the US and $B$ and the US are equal for Group 62E and do not give either stimulus an advantage in the compe- tition for any remaining associative strength. In contrast, for Group 105E, A begins $105 \mathrm{sec}$ prior to the US, while B begins only $62 \mathrm{sec}$ prior to the US. Element B should therefore better compete for any remaining associative strength, and, to that degree, unblocking (i.e., strong conditioning to B) might be expected.

Since both factors predict stronger conditioning to B in Group 105E than in Group 62E, these factors would have to be teased apart if the prediction were confirmed. As a step in this direction, a fourth group was included in the design. This group, Group 105C, received only the training given to Group 10SE in Phase 2. A comparison of Groups $105 \mathrm{C}$ and $62 \mathrm{C}$ in terms of conditioning to stimulus $B$ allows the second factor to be evaluated in isolation from the first. Thus, at the start of the training in Phase 2, these two groups would not differ in terms of the conditioned strength of element A. But in Group 105C, element $B$ would enjoy an advantage in the competition for associative strength relative to element $\mathbf{A}$. Only in Group $105 \mathrm{C}$ is the ISI more favorable for B than for A. Therefore, at the end of Phase 2 training, element $\mathrm{B}$ should be more strongly conditioned in Group 105C than in Group 62C (cf. Kehoe, Gibbs, Garcia, \& Gormezano, 1979). If, however, the second factor is not important but the first factor is, then Groups $105 \mathrm{C}$ and $62 \mathrm{C}$ should not differ, but Group 105E should show more conditioning to element B than should Group 62E. If neither factor is important, then the two controls should not differ from each other and the two experimentals should not differ from each other, but each experimental group should show less conditioning to $B$ than should its appropriate control.

There is a further consideration. In trace conditioning procedures, conditioning to the trace CS declines as the ISI increases, but conditioning to the contextual cues (which are present in the gap between CS termination and US onset) increases (Marlin, 1981). These contextual cues must therefore be considered as a third element, $\mathrm{C}$, in the compounds used here. If increases in the strength of element $\mathrm{C}$ compensate for decreases in the strength of element $\mathbf{A}$, then blocking effects might remain constant even when the ISI between A and the US is changed as described above. Further discussion of this possibility will be postponed until after the data from all three of the present experiments have been described.

\footnotetext{
Method

Subjects. The subjects were 32 male albino rats, 90 days old on arrival from the Holtzman Company, Madison, Wisconsin. They were housed individually under continuous illumination with free access to water and were maintained at $80 \%$ of their freefeeding body weights throughout the experiment.

Apparatus. The apparatus consisted of eight Gerbrands conditioning chambers measuring $23.2 \times 20.3 \times 19.5 \mathrm{~cm}$. Each chamber was housed in a ventilated $.61-\mathrm{m}$ cube of $12.7-\mathrm{mm}$ plywood lined with acoustical tile. The floors were made of 18 stainless
} 
steel rods, $2 \mathrm{~mm}$ in diameter and mounted $1.3 \mathrm{~cm}$ apart center to center. The end walls were aluminum; the side walls and ceiling were transparent Plexiglas. A standard $1.5 \times 5.0 \mathrm{~cm}$ Gerbrands response bar was located in the center of one end wall $8 \mathrm{~cm}$ above the grid floor. Located to the left of the bar on the same wall was a $5.5 \times 5.0 \times 5.0 \mathrm{~cm}$ dipper receptacle. Two $10-\mathrm{cm}$ speakers were mounted on the chamber lid. One was used to present a $1,000-\mathrm{Hz}$ tone $\mathrm{CS}$, which raised the background sound level produced by the exhaust fans in the chamber from 71 to $81 \mathrm{~dB}$ (re $20 \mu \mathrm{N} / \mathrm{m}^{2}$ ). The other was used to present white noise, which raised the sound level from 71 to $82 \mathrm{~dB}$. The noise, which was on throughout experimentation as a background masking stimulus, was louder than the tone CS but did not prevent that CS from being heard. Two $28-\mathrm{V}$ lights, operated simultaneously at $26 \mathrm{~V}$, served as a light CS. One was located on the chamber lid; the second was located on the front panel directly above the dipper feeder and $9.5 \mathrm{~cm}$ above the floor. When these lights were not on, the chamber was totally dark. Scrambled grid shocks (USs) were provided by eight Grason-Stadler shock sources and scramblers (Models E1064GS and 700); they were $1 \mathrm{~mA}$ in intensity and $1 \mathrm{sec}$ in duration. The measured baseline response, barpressing, was reinforced with 4-sec presentations of a .1-ml dipper containing $32 \%$ (by weight) sucrose.

Procedure. All rats were first trained to approach and lick a dipper containing sucrose. Next, they were left in the chamber while sucrose was delivered once every minute for 20 min regardless of responding. Following this, the rats were shaped to barpress. For the next 2 days, each response was reinforced until the rats had obtained on each day approximately 90 reinforcers. On the next day, the rats received one 2-h session during which responding was reinforced on a VI 1-min schedule. For the next 5 days, responding was reinforced on a VI 2 -min schedule during daily 2 -h sessions. All subsequent sessions were $2 \mathrm{~h}$ long, and barpressing was always reinforced on a VI 2 -min schedule.

In the A-pretraining phase, the rats were divided into four groups of eight, designated $62 \mathrm{E}, 62 \mathrm{C}, 105 \mathrm{E}$, and $105 \mathrm{C}$. Here, the number indicates the interstimulus interval (ISI) in seconds between the onset of the CS and the onset of the US. The letter indicates whether the group was a blocking experimental $(E)$ or control (C) group. One of the two experimental groups (Group 105E) received trials with a $2-\mathrm{sec}, 1,000-\mathrm{Hz}$ tone that began $105 \mathrm{sec}$ prior to the onset of the 1-sec, 1-mA grid-shock US. The other experimental group (Group 62E) received trials with the same $2-\mathrm{sec}$ tone beginning $62 \mathrm{sec}$ before the onset of the shock US. For both groups, four CS-US pairings (trials) were randomly placed within the session. During these same sessions, the two control groups (Groups $62 \mathrm{C}$ and $105 \mathrm{C}$ ) received only VI training with no superimposed CS or US presentations. This A pretraining phase continued for 5 consecutive days.

For the next 3 days, all groups received four daily conditioning trials with a compound CS consisting of the 2-sec tone (stimulus A) and the 2-sec light (stimulus B). For Groups 105E and $105 \mathrm{C}$, the compound was a serial compound; the 2 -sec tone (A) began $105 \mathrm{sec}$ before the onset of the shock US, while the 2-sec light (B) followed the tone and began $62 \mathrm{sec}$ before the onset of the shock US. For Groups $62 \mathrm{E}$ and $62 \mathrm{C}$, the compound was a simultancous compound; the 2-sec light and the 2-sec tone CS began simultaneously $62 \mathrm{sec}$ before the onset of the shock US. ${ }^{1}$

Two daily VI 2-min recovery sessions followed AB training. These recovery sessions were designed to increase the barpress baseline response rates in the event that they were depressed by shock presentations in the previous phases so that suppression to $A$ and $B$ could be accurately measured later in testing.

Twelve days of testing began on the day following recovery. For the first 6 test days, one reinforced light trial occurred in each 2-h session. In these "savings" tests for conditioning to the target, light CS (stimulus B), the 2-sec light began $62 \mathrm{sec}$ before the onset of the shock US. For the next 6 days, extinction tests for conditioning to the pretrained A stimulus, tone, were conducted. One presentation of the 2-sec tone CS occurred in each 2-h session, with no subsequent US occurrence. Suppression was measured in the 60-sec period that followed each CS.

Annau-Kamin (1961) suppression ratios were computed for all training and test trials. This ratio is $D /(D+B)$. In the present study, $D$, unless noted otherwise, represents the response rate during the 60 -sec period just prior to the onset of the shock US; $B$ represents the response rate (per minute) during the 3-min period just prior to the onset of the CS. For serial compound groups, the $\mathrm{B}$ period was the $3 \mathrm{~min}$ just prior to the onset of the firstoccurring $C S$ in the series. The suppression ratio is 0 if suppression in the $\mathrm{D}$ period is complete and .50 when no suppression occurs. In some cases, as will be indicated, a suppression ratio was calculated for the $45 \mathrm{sec}$ immediately following presentation of the first CS in the serial-compound groups. In this case, the D component of the equation was the response rate (per minute) during the 45-sec period, which included the 2-sec presentation of the second CS.

\section{Results and Discussion}

Group mean pre-CS response rates tended to increase across phases from roughly 16 responses/min in A training to roughly 27 responses/min during A extinction testing. Within any single phase, the group means were very homogeneous; the largest difference between any pair of groups occurred in the A extinction test and was 10 responses/min. In no phase of the experiment were reliable differences found in preCS rates between either blocking experimental and control groups or groups conditioned at 105- vs. 62sec ISIs $\left[\mathrm{Fs}_{\mathrm{s}}(1,28) \leqslant 1.30\right.$, ps $\left.>.05\right]$.

A pretraining. Figure 1, panel $\mathrm{A}$, shows the results of A pretraining. These results agree with those of Kamin (1965) in showing that the group with the shorter ISI (Group 62E) showed more suppression than the group with the longer ISI (Group 105E). A mixed design analysis of variance of these data indicated that this effect of ISI on conditioning in the two groups was significant $[F(1,14)=11.69, p<$ $.01]$. In addition, a significant effect of day of conditioning was found, reflecting the daily growth of suppression in both groups $[F(4,56)=19.80, p<.01]$.

AB training. The data from $\mathrm{AB}$ compound training appear in Figure 1, panel B. No significant effect of ISI on conditioning was found, and there was no significant difference in suppression between the experimental groups combined (Groups 105E and 62E) and the control groups combined (Groups 105C and $62 \mathrm{C})[\mathrm{Fs}(1,28) \leqslant 2.30$, ps $>.05]$. However, a significant effect of day of conditioning was found $[F(2,56)=54.09, p<.01]$, indicating that the groups did acquire suppression in this phase. In addition, several significant interactions were found (ISI $X$ experimental/control, $F(1,28)=12.35, p<.01$, and experimental/control $\times$ day of conditioning, $F(2,56)$ $=8.11, \mathrm{p}<.01]$. This latter interaction may reflect the fact that the different groups acquired suppression at different rates. Specifically, probably as a result of its previous experience in A pretraining, Group 62E showed strong suppression throughout 


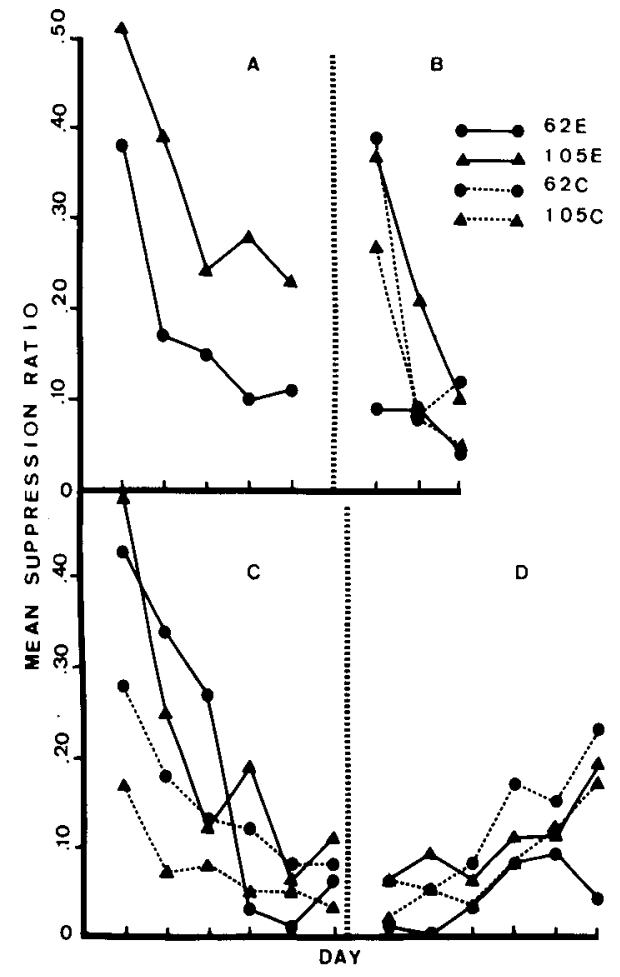

Figure 1. Daily mean suppression ratios for $A$ pretralning (panel A), AB compound training (panel B), the B savings test (panel C), and the $A$ extinction test (panel D) for each group in Experiment 1.

AB training, whereas the other three groups began this phase initially unsuppressed and gradually acquired suppression to the $\mathrm{AB}$ compound.

The interaction of ISI with treatment (experimental vs. control) mentioned above may reflect the fact that Group 105E showed minimal suppression on the 1 st day of training. Indeed, Group 105E showed less suppression to the tone-light compound on the 1st day of $\mathrm{AB}$ training than to the tone alone on the last day of pretraining. Table 1 shows the suppression during the first $45 \mathrm{sec}$ and the last $60 \mathrm{sec}$ of the 105-sec ISI for Group 105E and the suppression in Group 62E for the last day of $A$ pretraining and the 1st day of $\mathrm{AB}$ training. The loss in suppression for Group 105E from $A$ pretraining to $A B$ compound training is seen only in the last $60 \mathrm{sec}$ of the 105-sec ISI (after the novel $B$ stimulus was presented) and does not occur in Group 62E. A paired $t$ test was performed on these data for Group 105E, and a significant loss in suppression was found from the last day of $A$ pretraining to the 1st day of $\mathrm{AB}$ training $[\mathrm{t}(7)=2.83, \mathrm{p}<.05]$. Kamin $(1968,1969)$ found a loss in suppression on the first trial of compound training when CSs were simultaneously compounded in a forward delay procedure. In the present experiment, only the serial compound produced a significant loss in suppression.

In general, both Kamin's result and the present finding seem to be instances of Pavlov's "external inhibition." Pavlov (1927/1960) frequently found that superimposing a novel stimulus on a previously conditioned stimulus would temporarily disrupt the CR to the latter. The serial compound procedure in this study seems to be especially sensitive to this effect. Why it should be more sensitive than the simultaneous compound procedure is unclear. It may be that the trace of the pretrained CS is weaker at the moment the novel CS is presented, thus making control by the pretrained CS easier to disrupt. Or, it may be that the CR established with the 105-sec ISI is weaker (and, hence, easier to disrupt) than that established by the 62-sec ISI.

B savings tests. Figure 1, panel $\mathrm{C}$, shows the data from the savings test for conditioning to the light CS, stimulus B. The figure shows that initially the two experimental groups suppressed less to the light than did the control groups $[F(1,28)=9.67, p<.01]$. Simple-effects tests were conducted on the first three trials of testing. Only the first three trials were analyzed in these tests because a convergence of the groups' suppression scores was expected over trials. The error term and the df used for these $t$ tests were derived from the overall analysis of variance. These tests showed that Group 62E suppressed significantly less than Group $62 \mathrm{C}[\mathrm{t}(28)=3.40, \mathrm{p}<.01]$ and that Group 105E suppressed significantly less than did Group 105C $[\mathrm{t}(28)=4.06, \mathrm{p}<.01]$. Thus, blocking did occur with both serial and simultaneous compounds in trace conditioning procedures.

Because stimulus A was more weakly preconditioned in Group 105E than in Group 62E and because the ISI in AB training favored B over A in Group 105E but not in Group 62E, Group 105E was expected to show more suppression to stimulus B. Over the first three trials, the mean suppression ratio for Group 62E was .35; that for Group 105E was .28. The difference was in the predicted direction but was not significant $[t(28)=1.46, p>.05]$. Because stimulus $B$, relative to $A$, enjoyed the advantage of a shorter ISI in the competition for associative strength for Group $105 \mathrm{C}$ relative to Group $62 \mathrm{C}$, Group $105 \mathrm{C}$ was expected to show greater suppression to stimulus B. Over the first three trials, the mean suppression ratio for Group $62 \mathrm{C}$ was .20; that for Group $105 \mathrm{C}$ was

Table 1

Mean Suppression Ratios for Groups 62E and 105E of Experiment 1 on the Last Day of A Pretraining (L-A) and the First Day of AB Compound Training (1-AB)

\begin{tabular}{rrrrrr} 
& \multicolumn{2}{c}{$60-S e c$ Measure } & & \multicolumn{2}{c}{$45-S e c$ Measure } \\
\cline { 2 - 3 } \cline { 5 - 6 } Group & L-A & $1-\mathrm{AB}$ & & L-A & $1-\mathrm{AB}$ \\
\hline $105 \mathrm{E}$ & .22 & .37 & .20 & .18 \\
$62 \mathrm{E}$ & .11 & .09 & & \\
\hline
\end{tabular}


.11 The difference was in the right direction and was reliable $[\mathrm{t}(28)=2.11, \mathrm{p}<.05]$.

A extinction test. The results of $A$ testing are of interest for two reasons. First, such results are rarely reported in the blocking literature, and, second, the inverse hypothesis makes strong predictions about what should be observed in such tests. This hypothesis assumes that elements compete for a limited amount of associative strength. If two initially neutral elements are equally salient and are reinforced in compound, then at asymptote each should control about half of the available associative strength. But if one of them is asymptotically conditioned to begin with, then at the end of compound training, that element should control nearly all of the available associative strength. Thus, element $\mathbf{A}$ should be much more highly conditioned for blocking experimental groups than for blocking control groups.

The data bearing on this prediction are shown in Figure 1, panel D, and they clearly do not support it. The only significant effect found in A testing was that of day of conditioning $[\mathrm{F}(5,140)=8.61, \mathrm{p}<$ $.01]$, reflecting the course of extinction in all groups. It could be argued that early in the extinction test a ceiling effect obscured the expected differences among groups. This argument applies less, however, toward the end of testing, at which point Groups 105E and $105 \mathrm{C}$, at least, look very similar (see, also, Experiments 2 and 3 to follow).

In general, the results of Experiment 1 give mixed support to the various predictions derived from the inverse hypothesis: Relative to Group 62E, Group $105 \mathrm{E}$ did not suppress significantly more to element $B$ in the savings test, despite the fact that element $\mathbf{A}$ was more weakly conditioned in Phase 1 and despite the fact that, in Group 105E, the B element enjoyed a competitive advantage for any remaining associative strength in Phase 2. It is true that Group $105 \mathrm{C}$ did show significantly stronger conditioning to element B than did Group $62 \mathrm{C}$, as predicted by the inverse hypothesis, but the same hypothesis seemed to fail badly in predicting the results of the A extinction tests.

Because the results of Experiment 1 are not entirely clear with regard to the predictions described above, they leave us uncertain about the cause of the unblocking observed in the unpublished context-blocking studies mentioned in the introduction. However, the results are unequivocal in the empirical information they provide about blocking in trace conditioning procedures. Specifically, they confirm previous findings that blocking can occur in trace conditioning (e.g., Gray, 1978) and with both simultaneous and serial trace compounds. Experiment 2 sought to extend these empirical observations and, simultaneously, to retest the prediction of the inverse hypothesis concerning differences between blocking experimental and control groups during $\mathbf{A}$ extinction testing.

\section{EXPERIMENT 2}

Experiment 1 found that the preconditioned element $\mathrm{A}$ blocked conditioning to $\mathrm{B}$ both when $\mathrm{A}$ and $B$ were presented in a simultaneous compound and when A preceded B in a serial compound. Experiment 2 assessed the generality of these findings by determining whether a preconditioned element $\mathbf{A}$ would block conditioning to $\mathrm{B}$ if $\mathrm{B}$ preceded $\mathrm{A}$ in a serial compound. The question of whether A could block conditioning to $\mathbf{B}$ under these conditions seemed interesting for a number of reasons, perhaps the most salient of which is that when $B$ precedes the preconditioned $A$, it stands in a position to gain second-order conditioned strength from A (cf. Kehoe, Gibbs, Garcia, \& Gormezano, 1979). It seemed possible that such potential second-order conditioning might attenuate or even eliminate blocking to $\mathrm{B}$.

The experiment also sought to reassess the prediction of the inverse hypothesis that, following compound training, the blocking experimental groups should show stronger conditioning to element $\mathbf{A}$ than should the blocking control groups. Experiment 1 did not find this result when it examined conditioning to $A$ in an extinction test given after a savings test for conditioning to element $\mathrm{B}$. It seemed possible that the predicted differences might have been more easily detected if the extinction test for conditioning to stimulus $\mathbf{A}$ had preceded the savings test for conditioning to stimulus B. Experiment 2, therefore, sought to test this possibility.

The design included a blocking experimental group and a blocking control. The experimental group received in Phase 1 conditioning to stimulus $\mathrm{A}$ and received in Phase 2 conditioning to a serial compound consisting of B followed by A. The only conditioning the control group received was that given in Phase 2. Following Phase 2, the two groups were subdivided for testing. Half the rats in each group were given the savings test to stimulus $B$ before being given the extinction test to stimulus $A$. For the remaining rats in each group, the reverse was true.

\section{Method}

Subjects and Apparatus. Thirty-two albino rats, similar to those in Experiment 1, were used, and they were maintained as before. The apparatus, CSs, and USs were the same.

Procedure. Preliminary training proceeded as in Experiment 1. Next, the rats were divided into four groups of eight, designated $\mathrm{BAE}, \mathrm{ABE}, \mathrm{BAC}$, and $\mathrm{ABC}$. Here, the first two letters indicate the order in which the two stimuli, $A$ and $B$, were tested. The third letter indicates whether the group was a blocking experimental (E) or control (C) group.

During A pretraining, the experimental groups, Groups BAE and $A B E$, received four conditioning trials in each of five daily sessions with the onset of the 2-sec tone (stimulus A) followed $62 \mathrm{sec}$ later by the shock US. The control groups, Groups ABC and $B A C$, received only VI training with no CS or US presentations.

During AB training, all groups received four trials in each of three daily sessions with the 2-sec light (stimulus B), and the 2-sec tone (stimulus A). For all groups, a 2-sec presentation of stim- 
ulus $B$ began $43 \mathrm{sec}$ before the onset of a 2 -sec presentation of stimulus A and $105 \mathrm{sec}$ before the shock US; thus, A began $62 \mathrm{sec}$ before the onset of the shock US. Two VI 2-min recovery sessions followed $\mathrm{AB}$ conditioning, as in Experiment 1.

Following recovery, Groups $\mathrm{BAE}$ and $\mathrm{BAC}$ received 6 days of a savings test for conditioning to element $B$ and then 6 days of an extinction test for conditioning to element $A$. In contrast, Groups $\mathrm{ABE}$ and $\mathrm{ABC}$ received these tests in the opposite order. During the savings test, all groups received one trial each day with the onset of the 2-sec B element followed 105 sec later by the shock US. The A extinction test trials were as described in Experiment 1.

\section{Results and Discussion}

Group mean pre-CS response rates were comparable to those of Experiment 1, and, as before, no significant differences in these rates were found in any phase of this study between the experimental and control groups or between groups receiving different orders of A and B testing [Fs $(1,28)<2.25$, ps $>.05]$.

A pretraining. During $A$ pretraining, the two blocking experimental groups (Groups BAE and $A B E$ ) acquired suppression to $A$ at similar rates, and an analysis of variance revealed no significant differences between them $(F<1)$. The only reliable effect was that of day of conditioning $[F(4,56)=18.69$, $\mathrm{p}<.01$ ], reflecting the daily growth of suppression in both groups.

AB training. During AB compound training, a statistically significant difference was found between the experimental and control groups $[F(1,28)=$ $13.16, p<.01]$. This difference reflected the fact that the experimental groups were already suppressed at the start of AB training while the control groups gradually acquired suppression over days. A significant interaction of day of conditioning with treatment (experimental or control) supports this statement $[F(2,56)=15.61, p<.01]$. Note that the external inhibition effect that occurred in Experiment 1 did not occur here, probably because the novel $B$ stimulus occurred before the pretrained $A$ stimulus rather than after it as in Experiment 1.

Figure 2 shows the trial-by-trial acquisition of suppression to the $A B$ compound for the two experimental groups combined (ABE + BAE) and for the two control groups combined ( $A B C+B A C)$. In this case, a suppression ratio was computed for both the first $45 \mathrm{sec}$ of the trace interval following presentation of the novel B stimulus (see top panel) and the last $60 \mathrm{sec}$ following presentation of the pretrained $A$ stimulus (see bottom panel). Note that, throughout training, the experimental groups showed strong suppression to the pretreated A cue (see circles in bottom panel) and little suppression to the novel B (see circles in the top panel). The control groups, on the other hand (see triangles), showed little suppression to either stimulus initially, but quickly acquired it to both. Note that over the course of training, the acquisition of suppression to B (top panel) was retarded in the experimental groups as compared with the con-

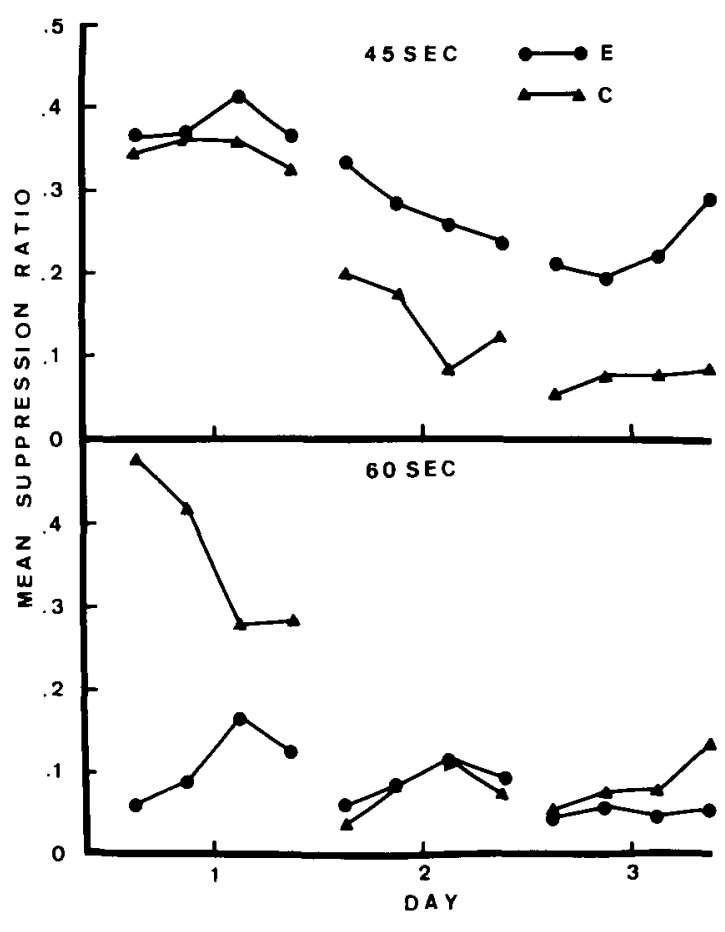

Figure 2. Mean trial-by-trial suppression during the B-then-A serial compound training of Experiment 2. In both panels, the two experimental groups have been combined and the two control groups have been combined. The top panel shows the suppression in the first 45 sec that followed the onset of element $B$. The bottom panel shows the suppression in the 60 sec that followed the termination of element $A$ in the $B$-then-A compound.

trols. This is, in effect, a demonstration of blocking in progress, a demonstration made possible by the use of a serial compound

Although conditioning to B was clearly retarded in the experimental groups, Figure 2 suggests, nevertheless, that B gradually acquired a moderate level of conditioned strength over trials. This impression was supported by a one-way analysis of variance of the data on the suppression to stimulus B for the experimental groups. In this analysis, the only factor was trials, and this effect was significant $[F(11,165=$ $4.74, \mathrm{p}<.01]$.

This finding is of potential theoretical importance. It could reflect the growth of excitation to B based on its forward pairing with $A$ (i.e., second-order conditioning), or it could reflect a growth of excitation to $B$ based on its forward pairing with the shock US. If it reflects the latter, it argues against a theoretical proposal by Mackintosh (1975a, 1975b). Mackintosh has argued that no blocking occurs on the first compound trial, but that, on subsequent trials, the animal "learns to ignore" the added B stimulus. In the usual blocking procedure, in which $A$ and $B$ are simultaneously compounded, Mackintosh's proposal is difficult to test because attention to B cannot be separated from attention to $A$. In the present experi- 


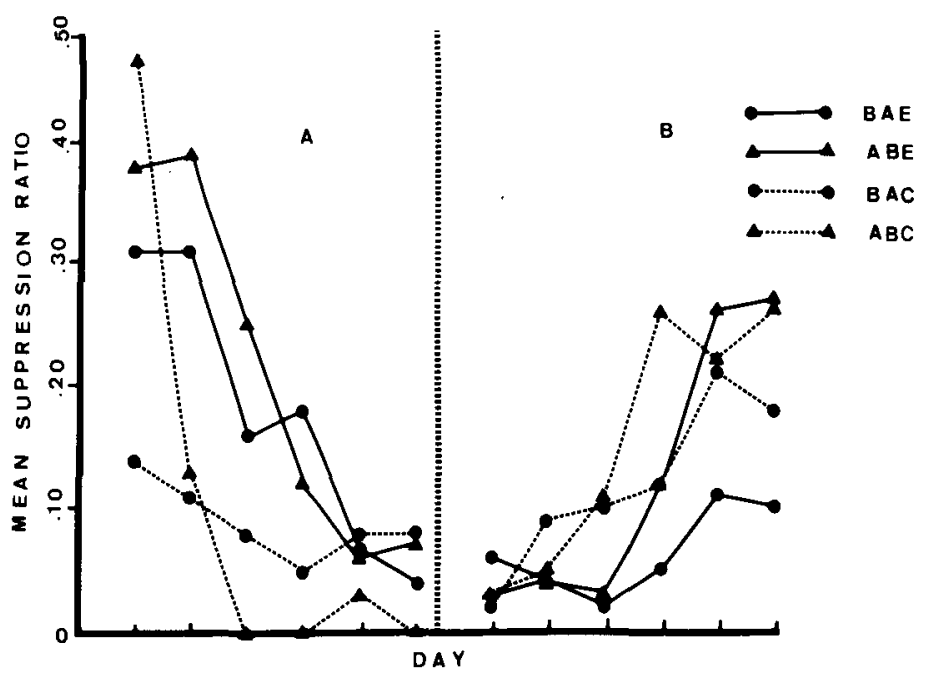

Figure 3. Daily suppression ratios for the B savings test (panel A) and the $\mathbf{A}$ extinction test (panel B) for each group in Experiment 2.

ment, in which is was possible to separate attention to $\mathbf{A}$ and $\mathrm{B}$, the experimental rats did not appear to be "learning to ignore" $B$; nevertheless, as we shall see below, conditioning to $\mathrm{B}$, as measured in the $\mathrm{B}$ savings test, was undeniably blocked.

B savings test. Figure 3, panel A, shows the data from the savings test for conditioning to the target element B for all groups. These results show an overall blocking effect. An analysis of variance showed that, overall, the experimental groups suppressed less to $\mathrm{B}$ than did the controls $[\mathrm{F}(1,28)=6.17, \mathrm{p}<.05]$. Simple-effects tests similar to those described in Experiment 1 performed on the data from the first three trials of testing showed that Group BAE suppressed significantly less than Group BAC $[\mathrm{t}(28)=3.17$, $\mathrm{p}<.01$ ] and that Group ABE suppressed significantly less than Group $A B C[t(28)=2.90, p<.01]$. Thus, blocking occurred in this experiment despite the presence of an embedded second-order conditioning paradigm.

As shown in Figure 3, panel A, a surprising result occurred on the first savings trial for Group ABC. This group, which received extinction test trials for conditioning to A prior to the savings test for conditioning to $\mathrm{B}$, failed to suppress to $\mathrm{B}$ on the first trial. Table 2 provides a more detailed analysis of the data; it shows that the rats in Group ABC actually did suppress for the first $45 \mathrm{sec}$ after the presentation of element $B$ and that only in the last $60 \mathrm{sec}$, the interval that had followed the presentation of element $A$ during compound training, did they cease suppressing. (A loss in suppression in this same interval also occurred in Group BAC, but to a much lesser extent.) Thus, the extinction of conditioning to the A element prior to testing $B$ may have influenced the suppression seen in the last $60 \mathrm{sec}$ of the savings test for conditioning to $\mathrm{B}$.
One explanation of the loss in suppression that occurred for Group ABC in the last $60 \mathrm{sec}$ of the CSUS interval is that it reflects a generalization of extinction from A to B. However, if generalization of extinction occurred, why was it limited to the last $60 \mathrm{sec}$ of the trace interval? A second explanation might be that the stimulus conditions in testing (single-stimulus presentations) differed from those in the immediately preceding training (compound-stimulus presentations), resulting in a loss of excitation in testing (generalization decrement). If this were the case, then a similar loss in suppression should have occurred in Group BAC. Although a loss in suppression in the last $60 \mathrm{sec}$ did occur in this group, it was not as large as that seen in Group ABC. A third explanation might be that the $B$ cue plus a temporal cue $(45 \mathrm{sec})$ in some manner evoked a representation of $A$ from memory (Wagner, 1976). Since conditioning to A was previously extinguished for Group ABC, no US (or, at most, a "degraded" US representation; Rescorla \& Heth, 1975) was associated with $\mathbf{A}$, and, therefore, suppression was alleviated.

A extinction test. The results of the A extinction test appear in Figure 3, panel B, which shows that the experimental groups did not suppress signif-

Table 2

Mean Suppression Ratios for All Groups in Experiment 2 on the First Day of the Savings Test for Conditioning to Stimulus B

\begin{tabular}{ccc}
\hline & \multicolumn{2}{c}{ Measure } \\
\cline { 2 - 3 } Group & $45 \mathrm{Sec}$ & $60 \mathrm{Sec}$ \\
\hline BAE & .28 & .31 \\
ABE & .35 & .38 \\
BAC & .07 & .14 \\
ABC & .21 & .47 \\
\hline
\end{tabular}


icantly more than the controls $[\mathrm{F}(1,28)=1.36, \mathrm{p}>$ $.05]$. This was true even though the $A$ cue had successfully blocked conditioning to element B more for experimentals than for controls. These results confirm the findings of Experiment 1 and show that the latter were not due to the order in which the components of the compound were tested. Once again, these results do not seem to be consistent with the predictions of the inverse hypothesis, and this inconsistency seems surprising in view of the previous success of the hypothesis in accounting for a large body of literature (Rescorla \& Wagner, 1972; Wagner \& Rescorla, 1972). Experiment 3, therefore, sought to assess yet another possible reason why the predicted differences between experimental and control groups were not obtained in the extinction tests for conditioning to stimulus $\mathbf{A}$.

\section{EXPERIMENT 3}

As discussed previously, the inverse hypothesis predicts that, following training to the $\mathrm{AB}$ compound, stimulus A should be much more highly conditioned for experimental groups for which A was preconditioned than for controls for which it was not. This prediction, however, is affected by the relative salience of the two stimuli. If element $A$ is considerably more salient than element $B$, then $A$ will have a decided edge in the competition for associative strength, both for the experimental group for which $\mathbf{A}$ is pretrained and for the control group for which it is not. In fact, the greater the salience of $A$ relative to $B$, the more difficult it will become to detect a difference between the experimental and control groups in terms of their conditioning to stimulus A following the compound conditioning phase.

In Experiments 1 and 2, the tone stimulus always served as element $\mathbf{A}$ and the light stimulus always served as $B$. If the tone were much more salient than the light, then group differences in the A extinction tests would be hard to detect, as just explained. The differences should be easier to detect if the light served as $\mathbf{A}$ and the tone as B. Support for this idea can be found in a study of conditioning of the nictitating membrane response performed by Marchant and Moore (1973). These investigators found that when the more salient of their two stimuli served as the pretrained A stimulus, no difference occurred between experimental and control groups in a subsequent test for conditioning to stimulus A. However, when the less salient stimulus served as the pretrained A stimulus, the predicted differences between experimental and control groups did emerge.

In Experiment 3, the light, which served as the B stimulus in the previous two experiments, served as the pretrained $A$ stimulus; and the tone, which served as the pretrained A stimulus in Experiments 1 and 2 , served as the added stimulus. Thus, any inequality in the salience of $\mathrm{A}$ and $\mathrm{B}$ in Experiments 1 and 2 was reversed for Experiment 3.

\section{Method}

Subjects. Sixteen male albino rats, approximately 90 days old and similar to those of Experiments 1 and 2, were maintained as before. Some of the rats had previously been shaped to barpress for Noyes pellets in an apparatus similar to that used here. In addition, some had experienced a single 2 -h session of discrimination training. In that session, barpressing was reinforced on a simple schedule (FR, VR, FI, or VI) in the presence of a cue light and nonreinforced in its absence.

Apparatus. The apparatus, CSs, and US were unchanged from Experiments 1 and 2.

Procedure. Preliminary training proceeded exactly as before. Afterwards, the rats were divided into two groups of eight. During A pretraining, the experimental blocking group (Group E) received four trials in each daily 2 -h session. On each trial, the 2 -sec light CS began $105 \mathrm{sec}$ before the onset of the shock US. The control group (Group C) received continued VI training with no superimposed CS or US presentations. Pretraining of element A continued for 5 days.

During AB training, both groups received four trials in each 2-h session. On each trial, the 2-sec light (stimulus $A$ ) and the 2 -sec tone (stimulus B) were presented. For both groups, the 2-sec light (A) began $105 \mathrm{sec}$ before the onset of the shock US, while the 2-sec tone (B) began $62 \mathrm{sec}$ before the onset of the shock US. Two VI 2-min recovery days immediately followed $A B$ training.

Following recovery, both groups received 6 days of savings tests for conditioning to element $B$ and then 6 days of extinction tests for conditioning to element $\mathbf{A}$. In the savings test for conditioning to $B$, the $2-\mathrm{sec}$ tone occurred $62 \mathrm{sec}$ before the onset of the shock US, while in the extinction test for conditioning to A, the 2-sec light was nonreinforced. Suppression to the elements in both tests was measured as before.

\section{Results and Discussion}

Group mean pre-CS response rates resembled those obtained in Experiments 1 and 2, and again no differences in these rates were found in any phase of this experiment between the control and the experimental group.

A pretraining. During the pretraining of stimulus $\mathbf{A}$, the experimental group acquired suppression in an unremarkable manner. The normalcy of this acquisition function was of some concern, however, because of the brief operant discrimination training involving a cue light that these subjects had experienced previously. Therefore, the acquisition results from these rats were compared with those of a naive group run under identical conditions in an unreported study. This comparison failed to find any statistical difference in the acquisition of suppression to the light in this experiment and the unreported experiment $(\mathrm{F}<1)$.

$\mathbf{A B}$ training. No difference in level of suppression was found between Groups $E$ and $C$ in $A B$ training. The only statistically significant effect was that of day of conditioning $[F(2,28)=30.58, p<.01]$, indicating the daily growth of suppression in both groups. In this experiment, unlike Experiment 1, only mini- 
mal evidence was obtained for an effect due to the presentation of the novel element B $43 \mathrm{sec}$ after the onset of the pretreated element A. Specifically, in the $60 \mathrm{sec}$ prior to shock, the mean suppression ratio for Group E was .17 on the first trial of the last session of A training, but .32 on the first trial of $A B$ training. This apparent external inhibition effect on the first trial was not significant as measured by a paired $t$ test $[t(7)=1.95, .05>p<.10]$.

B savings test. Figure 4 , panel $A$, shows that the experimental group (Group E) exhibited less suppression to the B stimulus than did the control (Group C) during the savings test $[F(1,14)=6.66, p<.05]$. That is, blocking occurred. Thus, the light stimulus, used in Experiments 1 and 2 as the added B stimulus, can block conditioning to the tone stimulus. In addition, a significant effect of days was found $[F(5,70)$ $=7.43, \mathrm{p}<.01]$, reflecting the daily growth of suppression to $B$ in both groups.

A extinction test. Figure 4, panel B, suggests that, as in Experiments 1 and 2, no significant difference in suppression between the experimental and control groups occurred during the $A$ extinction test $(F<1)$. So the failure to find a difference in $A$ testing between experimental and control groups in this series of experiments was apparently not caused by any salience differences between the light and the tone.

The relative salience of the light and tone can, however, be assessed more directly. One way is to examine the rate of conditioning to light and tone separately during the time that these stimuli served as stimulus $A$ in the $A$ pretraining phase of the various studies in this series. Combining data reported here with pilot data not described yielded six groups of eight rats trained with a $1-\mathrm{sec}, 1-\mathrm{mA}$ shock US. In all cases, four trials occurred in each daily 2-h session, superimposed on a VI 2-min reinforced barpress baseline. Two of the groups had been trained with the light as the A cue, and four groups had been trained with the tone as the A cue. A direct comparison of conditioning rates to the light and tone revealed no differences $(F<1)$. Given this information and the results of Experiments 1 and 2, it is not surprising that Experiment 3 failed to find a difference between the experimental and control groups in the extinction test for conditioning to stimulus $\mathrm{A}$. This failure is, however, still surprising from the point of view of the inverse hypothesis (for other failures, see Ayres \& Bombace, 1982; Cheatle \& Rudy, 1978; Vom Saal \& Jenkins, 1970, Experiment 1).

\section{GENERAL DISCUSSION}

The main results of these studies can be summarized as follows:

(1) When a preconditioned trace stimulus, A, was reinforced in a trace conditioning procedure in compound with a target element, B, conditioning to $B$ was blocked. The strength of this blocking effect was not significantly affected by A's conditioned strength as manipulated by varying the CS-US interval during the preconditioning of $\mathbf{A}$.

(2) Blocking to B occurred regardless of whether, during the compound conditioning phase, A preceded, occurred simultaneously with, or followed B. The strength of the blocking effect did not appear to be appreciably different in these different procedures.

(3) When $B$ preceded $A$ in the $A B$ compound, suppression to B-before-A increased significantly with training, suggesting that subjects attended to $B$ throughout compound conditioning.

(4) Following compound conditioning, the conditioned strength of the A element appeared to be similar in groups for which $\mathbf{A}$ had been pretreated rel-

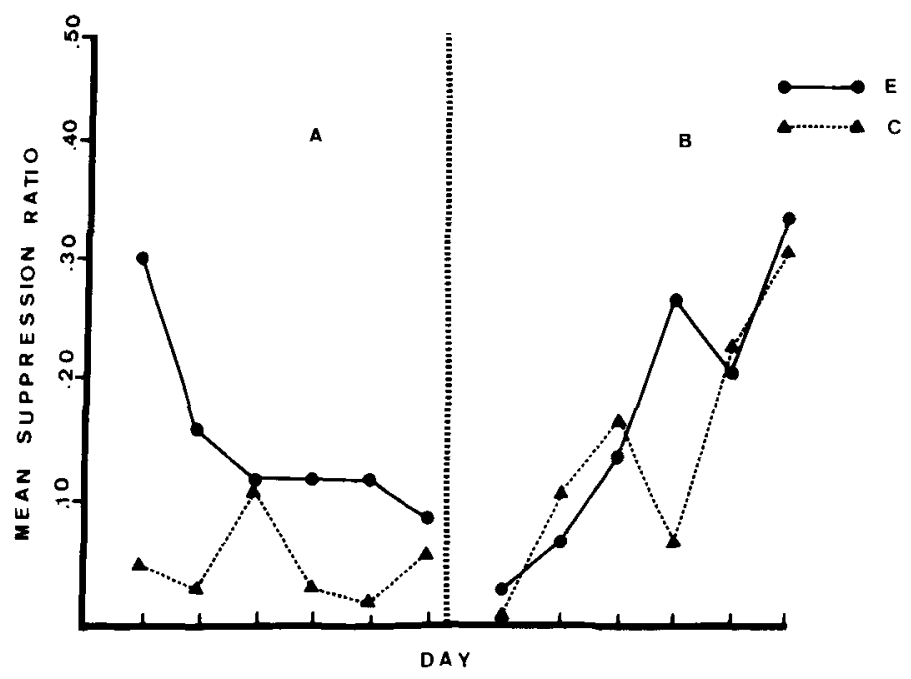

Figure 4. Daily mean suppression ratios for the B savings teat (panel A) and the $A$ extinction test (panel B) for each group in Experiment 3 . 
ative to groups for which it had not. This was true whether tests of A's strength preceded or followed tests of B's strength. It was also true whether A was tone and $B$ was light or vice versa.

After the present results were collected, another study of blocking, using simultaneous and serial compounds, was reported (Kehoe, Schreurs, \& Amodei, 1981). Like the present study, that research, which used the nictitating membrane response preparation in the rabbit, demonstrated blocking of conditioning to stimulus $B$ even though the interval between B and the US was more favorable for conditioning than was the interval between $A$ and the US. One difference in the results of the two reports is that, in the rabbit study, conditioning to $B$ at the end of $A B$ training did not appear to be blocked when $B$ preceded $A$ in the serial compound. However, potential differences in responding to $B$ in the experimental and control groups might have been obscured by a ceiling effect. If extinction tests had been given following $\mathrm{AB}$ compound training, the experimental group might have shown faster extinction, suggesting attenuated conditioning. On the other hand, if $A B$ training had been continued longer in the present study, no blocking to $B$ might have been found. Further work is needed to resolve the conflict. It is encouraging that conditioning to $\mathrm{B}$ appeared to be retarded during $\mathrm{AB}$ training for experimental rabbits relative to controls, just as it was in Experiment 2 of the present report. In the rabbit study, however, the retardation was apparently not significant.

As mentioned earlier, the first and fourth of the findings summarized above seem, on the surface, at least, to be inconsistent with the inverse hypothesis of the Rescorla-Wagner (1972) model. It may yet be possible, however, to devise an interpretation of these data that accounts for these results and at the same time reconciles the data with the model. Some progress toward this goal might be made by considering an interpretation that emphasizes the role of contextual stimuli (static apparatus cues) as stimuli that can block conditioning to discrete, target CSs (e.g., Tomie, 1976a, 1976b).

According to this interpretation, the pretreated A cue was preconditioned in compound with a context cue, $C$. The C "element" included all of the stimuli present in the conditioning chamber at the moment of reinforcement. $\mathrm{A}$ and $\mathrm{C}$ together shared in the available conditioned strength. When the CS-US interval for $\mathbf{A}$ was increased, weakening A's conditioned strength, the conditioned strength of $\mathrm{C}$ increased proportionally (Marlin, 1981). Thus, the strength of the AC compound for groups with differing ISIs was constant. Therefore, the ability of the AC compound to block conditioning to $B$ was unaffected by changes in A's temporal relation to the US. Similarly, A's temporal relation to the target element, $B$, during $\mathbf{A B}$ compound training was relatively unimportant because the $C$ element was always present at the moment the stimulus trace of $\mathrm{A}$ and $\mathrm{B}$ was reinforced.

The finding that the conditioned strength of the A element did not differ appreciably for groups for which A was preconditioned and groups for which it was not might also be understood in terms of a large role for the context cues. For example, imagine that, after $\mathrm{AB}$ compound training, the preconditioned A stimulus had gained, say, $10 \%$ of the available associative strength, while $90 \%$ of the available conditioned strength was controlled by $\mathrm{C}$, the context cues. The context cues were, after all, the cues most contiguous with the US presentation. For the sake of simplicity, imagine now that the B element had no associative strength at all, because conditioning to $\mathrm{B}$ had been blocked. Next, consider the control group. For the control group, imagine that element $\mathrm{C}$ still controlled $90 \%$ of the available conditioned strength, and $A$ and $B$ equally shared about $10 \%$. Notice that, although there is a difference in the amount of control by $\mathrm{A}$ in the two conditions, that difference is relatively small, only $5 \%$. Perhaps this explains why experimental and control groups in the present study did not differ in terms of their suppression to $\mathrm{A}$.

By the same logic, however, one could legitimately ask why the two groups differed in their suppression to B. Clearly, the difference between a little control $(5 \%)$ and no control is very small. Why is it possible to detect this small difference behaviorally? Perhaps the answer lies in the concept of variability: Where there is no control, there is no variability. So, detecting the difference between no control and a little control is easier than detecting the difference between a little control and a little more.

If the contextual-conditioning interpretation is correct, then it would seem that we should be able to find some evidence for context conditioning by examining pre-CS suppression. In the pre-CS periods, only the context cues were present. Presumably, the ideal place to look for such evidence would be the pre-CS period on the first trial of $\mathbf{A B}$ compound training. According to the hypothesis, the contextual cues should be highly conditioned only for the experimental groups. The previously presented analyses of pre-CS responding did not look specifically at this trial. If this crucial trial is examined, however, the pre-CS response rates for the experimental and control groups do not differ statistically [Experiments 1 and 2 , ts $(28) \leqslant 1.58$, ps $>.05$; Experiment 3, t(14) $=1.43, \mathrm{p}>.05$ ].

Although the analysis of pre-CS responding just presented does not offer strong support for the context-conditioning hypothesis under discussion, it should not be taken as a refutation of that hypothesis either. For example, recent evidence (Miller, Hartl, Capra, \& Balaz, Note 2) shows that a context cue presented in isolation may exert no measurable behavioral effect and yet potentiate the effects of a conditioned stimulus presented in that context. So, 
the absence of a behavioral effect by the context alone does not necessarily mean that the context is neutral or that its role is unimportant.

Finally, it if is true that stimulus A loses conditioned strength with increasing ISIs and that stimulus $\mathrm{C}$, the context cues in the CS-US interval, gain in strength to compensate for that loss, then how is it possible to demonstrate an ISI function in trace conditioning? If element $C$ gains strength to compensate for A's losses, then the total strength of the AC compound should remain constant regardless of ISI. Why then do rats suppress less in the CS-US interval when it is long than when it is short? And since they do suppress less when the ISI is long, doesn't this imply that the AC compound should be less capable of blocking conditioning to B? Clearly, this is a thorny problem for an analysis that emphasizes the role of these $\mathrm{C}$ cues in blocking. For problems like this to be resolved, we are somehow going to have to find a way to assess more directly than heretofore the role of these contextual cues on blocking in trace conditioning procedures.

\section{REFERENCE NOTES}

1. Ayres, J. J. B., \& Vigorito, M. Blocking, surprise, and postUS suppression in the conditioned suppression procedure. Paper presented at the 22nd annual meeting of the Psychonomic Society, Philadelphia, 1981.

2. Miller, R. R., Hartl, P., Capra, S., \& Balaz, M. Factors underlying contextual control of acquired behavior. Paper presented at the 21st annual meeting of the Psychonomic Society, St. Louis, Missouri, 1980.

\section{REFERENCES}

AnnaU, Z., \& Kamin, L. J. The conditioned emotional response as a function of intensity of the US. Journal of Comparative and Physiological Psychology, 1961, 54, 428-432.

Ayres, J. J. B., \& BoмвасE, J. C. A surprising extension of the preconditioned stimulus beyond the cotermination of the US and the added element does not alleviate blocking to the added element. Animal Learning \& Behavior, 1982, 10, 263-268.

Cheatle, M. D., \& Rudy, J. W. Analysis of second-order odoraversion conditioning in neonatal rats: Implications for Kamin's blocking effect. Journal of Experimental Psychology: Animal Behavior Processes, 1978, 4, 237-249.

Estes, W. K., \& Skinner, B. F. Some quantitative properties of anxiety. Journal of Experimental Psychology, 1941, 29, $390-400$.

GRAY, T. Blocking in the CER: Trace and delay procedures. Canadian Journal of Psychology, 1978, 32, 40-42.

Gray, T., Appignanesi, A. A. Compound conditioning: Elimination of the blocking effect. Learning and Motivation, $1973,4,374-380$.

KAMIN, L. J. Temporal and intensity characteristics of the conditioned stimulus. In W. F. Prokasy (Ed.), Classical conditioning, New York: Appleton-Century-Crofts, 1965.

KAMIN, L. J. "Attention-like" processes in classical conditioning. In M. R. Jones (Ed.), Miami Symposium on the prediction of behavior, 1967: Aversive stimulation. Coral Gables, Florida: University of Miami Press, 1968.

Kam in, L. J. Predictability, surprise, attention and conditioning. In B. A. Campbell \& R. M. Church (Eds.), Punishment and aversive behavior. New York: Appleton-Century-Crofts, 1969.

Kehoe, E. J., Gibas, C. M., Garcia, E., \& Gormezano, I.
Associative transfer and stimulus selection in classical conditioning of the rabbit's nictitating membrane response to serial compound CSs. Journal of Experimental Psychology: Animal Behavior Processes, 1979, 5, 1-18.

Kenoe, E. J., Schreurs, B. G., \& Amoder, B. Blocking acquisition of the rabbit's nictitating membrane response to serial conditioned stimuli. Learning and Motivation, 1981, 12, 92-108.

Kohler, E. A., \& Ayres, J. J. B. The Kamin blocking effect with variable-duration CSs. Animal Learning \& Behavior, 1979. 7, 347-350.

Mackintosh, N. J. Blocking of conditioned suppression: Role of the first compound trial. Journal of Experimental Psychology: Animal Behavior Processes, 1975, 1, 335-345. (a)

Mackintosh, N. J. A theory of attention: Variations in the associability of stimuli with reinforcement. Psychological Review, 1975, 82, 276-298. (b)

Marchant, H. G., III, \& Moore, J. W. Blocking of the rabbit's conditioned nictitating membrane response in Kamin's twostage paradigm. Journal of Experimental Psychology, 1973, 101, 155-158.

Marlin, N. A. Contextual associations in trace conditioning. Animal Learning \& Behavior, 1981, 9, 519-523.

Pavlov, I. P. Conditioned reflexes. New York: Dover, 1960. (Originally published, 1927.)

Resconla, R. A., \& HeTh, C. D. Reinstatement of fear to an extinguished conditioned stimulus. Journal of Experimental Psychology: Animal Behavior Processes, 1975, 104, 88-96.

Rescorla, R. A., \& Wagner, A. R. A theory of Pavlovian conditioning: Variations in the effectiveness of reinforcement and nonreinforcement. In A. H. Black \& W. F. Prokasy (Ëds.), Classical conditioning II: Current research and theory. New York: Appleton-Century-Crofts, 1972.

Tomie, A. Interference with autoshaping by prior context conditioning. Journal of Experimental Psychology: Animal Behavior Processes, 1976, 2, 323-334. (a)

Tomie, A. Retardation of autoshaping: Control by contextual stimuli. Science, 1976, 192, 1244-1246. (b)

Vom SaAl, W., \& Jenkins, H. M. Blocking the development of stimulus control. Learning and Motivation, 1970, 1, 52-64.

Wagner, A. R. Stimulus selection and a "modified continuity theory." In G. H. Bower \& J. T. Spence (Eds.), The psychology of learning and motivation (Vol. 3). New York: Academic Press, 1969.

Wagner, A. R. Priming in STM: An information-processing mechanism for self-generated or retrieval-generated depression in performance. In T. J. Tighe \& R. N. Leaton (Eds.), Habituation: Perspectives from child development, animal behovior, and neurophysiology. Hillsdale, N.J: Erlbaum, 1976.

Wagnen, A. R., \& Rescorla, R. A. Inhibition in Pavlovian conditioning: Application of a theory. In R. A. Boakes \& M. S. Halliday (Eds.), Inhibition and learning. London: Academic Press, 1972.

\section{NOTE}

1. Note that the ISI manipulation in A training was deliberately confounded with the type of compound conditioning (simultaneous or serial) given during $\mathrm{AB}$ training. This confound is necessary if one wishes to hold constant across groups the interval between $B$ and the US and hold constant across phases the interval between $A$ and the US. This confound should not alter the predictions from the inverse hypothesis. Group $62 \mathrm{E}$ should show weaker conditioning to element B than Group 105E because A should be more strongly conditioned for the former group and because subjects should presumably have more difficulty attending to $B$ when $A$ is physically present in the simultaneous compound condition than when $\mathrm{A}$ is not physically present as in the serial compound condition.

(Manuscript received August 21, 1981; revision accepted for publication April 20, 1982.) 